\title{
ANALISIS DAN PERANCANGAN SISTEM INFORMASI INVENTORY CONTROL BERBASIS VB.NET PADA PT. BEKAERT INDONESIA
}

\author{
Ahmad Solihin \\ Warehouse, \\ PT. Bekaert Indonesia, \\ Karawang, Indonesia, \\ ahmad.solihin279@gmail.com
}

\author{
Dudi Awalludin \\ Sistem Informasi, \\ STMIK Rosma, \\ Karawang, Indonesia, \\ dudi@rosma.ac.id
}

\begin{abstract}
ABSTRAK
PT. Bekaert Indonesia adalah salah satu perusahaan asing yang bergerak di bidang manufaktur. PT. Bekaert Indonesia mempunyai aktivitas pengolahan data tidak hanya terjadi dibagian Produksi, HRD, Finance, warehouse atau pun bagian lainnya baik yang berhubungan langsung dengan produksi, sumber daya, maupun keuangan sebuah perusahaan. Bagian warehouse merupakan bagian penting karena seluruh kegiatan produksi keterkaitan langsung dengan bagian ini. Setiap aktivitas yang ada di bagian gudang mulai dari penerimaan barang, pengecekan barang, meyimpan barang, dan mengeluarkan barang, sangat mempengaruhi aktivitas pada Inventory, sehingga pada bagian gudang harus dikelola dengan baik. Secara umum, dalam sebuah industri manufaktur, kegiatan inventori dimulai dari pemesanan bahan baku atau material lainya yang diperlukan dari pemasok. Sebelum bahan baku atau material digunakan, terlebih dahulu disimpan digudang untuk kemudian digunakan sesuai kebutuhannya. Hal yang sering terjadi pada persediaan adalah karena ketidakseimbangan antara kebutuhan bahan baku yang diperlukan oleh bagian produksi dengan ketersediaan bahan baku di gudang, sehingga perlu adanya sebuah sistem yang dapat membantu dalam mengendalikan persediaan bahan baku atau material. Untuk dapat memperbaiki permasalah tersebut maka perlu dilakukan suatu analisis terhadap sistem inventory control di PT Bekaert Indonesia yang hasil analisis dapat memperbaiki system sebelumnya sehingga sistem yang baru bisa menentukan estimasi kebutuhan material untuk periode mendatang dengan metode peramalan yang tepat, menetapkan jumlah material yang harus dipesan dan interval waktu pemesanan yang optimal, serta menetapkan safety stock yang optimal.
\end{abstract}

Kata Kunci: Inventory Control, Material, Analisis sistem, Bagian Gudang.

\section{ABSTRACT}

PT Bekaert Indonesia is one of foreign companies operating in manufacturing sector. One of the activity of PT Bekaert indonesia is processing the data was not only on production line, HRD, finance, the warehouse or the other part of that directly touch with the production, resources, and a company financial .Part the warehouse is an important element because all production activities direct effect with this part. Any activity that is in a part of the warehouse ranging from receipt of the goods, checking goods, for goods storage, and export of goods, intensely affecting activity on inventory, so that in a part of the barn must be managed well. Activity in the manufacturing industries in general inventori began of the order raw materials or material required of other suppliers. Before raw materials or material used, first on store in a warehouse for then in accordance with the need to protect. Problems often occurs in part because the imbalance between the needs of supplies are raw material that is required by the passage production with the availability of raw materials in a warehouse, so it needs the existence of an information systems that can be help in controlling supplies raw materials or material. To fix problems mentioned above, so one would have to do the analysis of inventory system control in PT Bekaert Indonesia that the results of the analysis could improve the system beforehand so that the new system able to determine estimation of a material to needs for the next period with a method of divination proper, set the amount of material one which must be ordered and intervals of time optimal reservations, and determining optimal safety stock.

Keywords: Inventory Control, Material, analysis system, warehouse

\section{PENDAHULUAN}

Pengendalian persediaan barang muncul sebagai akibat sering terjadi selisih antara tingkat penjualan atau kebutuhan dengan tingkat pemakaian. Karena Perhitungan kebutuhan barang ini diperoleh melalui demand dari konsumen.

Oleh karena itu, pengelolaan inventori yang baik sejalan dengan pengelolaan gudang yang 
baik. Karena gudang merupakan tempat penyimpanan barang yang harus dikelola dengan baik agar mendukung kelancaran proses dan memenuhi kebutuhan produksi.

Secara umum, dalam sebuah industri manufaktur, aktivitas inventori dimulai dari pemesanan barang atau material lainya yang diperlukan dari pemasok. Sebelum barang atau material digunakan terlebih dahulu disimpan digudang untuk kemudian digunakan sesuai kebutuhan.

Masalah yang sering terjadi dalam pengelolaan persediaan barang yaitu sering terjadi ketidaseimbangan antara persedian barang dengan kebutuhan produksi, sehingga akan mengakibatkan terhambatnya produksi. Untuk mencegah terjadinya ketidakseimbangan antara persediaan barang dengan produksi maka perlu adanya sebuah sistem informasi pengendalian persediaan barang yang dapat mengestimasi kebutuhan material untuk periode mendatang dengan metode peramalan yang tepat, menetapkan jumlah material yang harus dipesan dan interval waktu pemesanan yang optimal, serta menetapkan safety stock yang optimal untuk mengetahui peranan perencanaan dan pengendalian persediaan material dalam usaha meningkatkan efisiensi biaya persediaan yang akan menjaga kestabilan bahkan menurunkan biaya operasional dari sebuah perusahaan.

\section{Rumusan Masalah}

Berdasarkan uraian di atas maka rumusan masalah dalam penelitian ini adalah:

1. Bagaimana merancang suatu sistem inventory control pada PT. Bekaert Indonesia, sehingga bisa menstabilkan persediaan barang?

2. Bagaimana system bisa menentukan jumlah material yang harus dipesan dan interval waktu pemesanan yang optimal?

3. Bagaimana cara untuk menentukan estimasi kebutuhan material untuk periode mendatang dengan metode peramalan kebutuhan proses produksi yang tepat sesuai dengan planning yang diberikan oleh PPIC?

\section{Ruang Lingkup}

Ruang lingkup sangat penting untuk ditentukan terlebih dahulu sebelum sampai pada tahap selanjutnya. Sesuai dengan judul dan latar belakang masalah yang dijelaskan maka pembatasan permasalahan mengenai sistem informasi inventory control yang meliputi:

1. Menganalisis Sistem persediaan barang, mencakup estimasi kebutuhan material, pemesanan material, penerimaan material, persediaan material, safety stock, dan pengeluaran material.

2. Menganalisis dokumen yang terkait dengan system persediaan barang.

\section{TINJAUAN PUSTAKA}

Pada bagian akan dipaparan hasil studi literature untuk penelitian. Tinjauan pustaka berdasarkan judul penelitian.

Berdasarkan tinjauan pustaka Analisis sistem informasi pengendalian persediaan barang mencakup beberapa teori dasar dari dua (2) bidang ilmu yaitu Sistem Informasi dan Persediaan. Dari kedua bidang ilmu tersebut akan pemaparan akan dimulai dengan pemahaman tentang:

\section{Sistem Informasi}

Sistem adalah kumpulan komponen yang saling terkait yang berfungsi bersama-sama untuk mencapai hasil tertentu [9].

Sistem adalah beberapa elemen yang terintegrasi untuk mencapai tujuan dari perusahaan atau organisasi yang terdiri dari beberapa sumber daya dimana sumber daya tersebut bekerja untuk mencapai tujuan perusahaan atau organisasi tersebut [4].

Informasi adalah kumpulan fakta yang terorganisir sehingga mereka memiliki nilai tambah selain nilai fakta individu [11].

Informasi adalah data yang diolah menjadi bentuk yang lebih berguna bagi penerimanya [14].

Dari pengertian diatas dapat diambil kesimpulan bahwa sistem informasi merupakan kumpulan subsistem yang saling bersinergi pada aktifitas manajerian sehingga tercapainya target organisasi dengan menggunakan bantuan media komputer sebagai media pengolahan data menjadi informasi, dimana informasi tersebut bias dimanfaatkan oleh pihak internal dan eksternal.

\section{Pengendalian Persediaan/Inventory Barang}

Persediaan (inventory) sebagai sumber daya menganggur (idle resource). Sumber daya 
menganggur ini belum digunakan karena menunggu proses lebih lanjut [5].

Dalam sebuah perusahaan barang dan bahan penolong memiliki arti yang sangat penting, karena menjadi modal terjadinya proses produksi sampai hasil produksi. Pengelompokan barang dan bahan penolong bertujuan untuk pengendalian bahan dan pembebanan biaya ke harga pokok produksi. Pengendalian bahan diprioritaskan pada bahan yang nilainya relative.

\section{PEMBAHASAN DAN HASIL}

\section{Prosedur yang sedang berjalan}

Prosedur yang sedang berjalan merupakan sistem yang berlaku dan diterapkan atau digunakan di dalam perusahaan pada saat ini.

System yang berjalan memiliki beberapa prosedur, yaitu:

\section{Pengeluaran Barang}

1. Produksi

a. Melakukan permintaan material dengan membuat form Packing Material (PM) rangkap 2.

b. Menyerahkan form Packing Material (PM) kepada Warehouse.

c. Menerima form Packing Material (PM) lembar ke-1 yang sudah ditandatangani oleh Warehouse, kemudian diarsip menurut nomor.

2. Warehouse

a. Menerima form Packing Material (PM) dari Produksi, kemudian cek stok material apakah tersedia atau tidak. Jika tersedia, maka form Packing Material (PM) ditandatangani. Jika tidak tersedia, maka dilakukan pembelian.

b. Menyerahkan form Packing Material (PM) lembar ke-1 yang sudah ditandatangan.

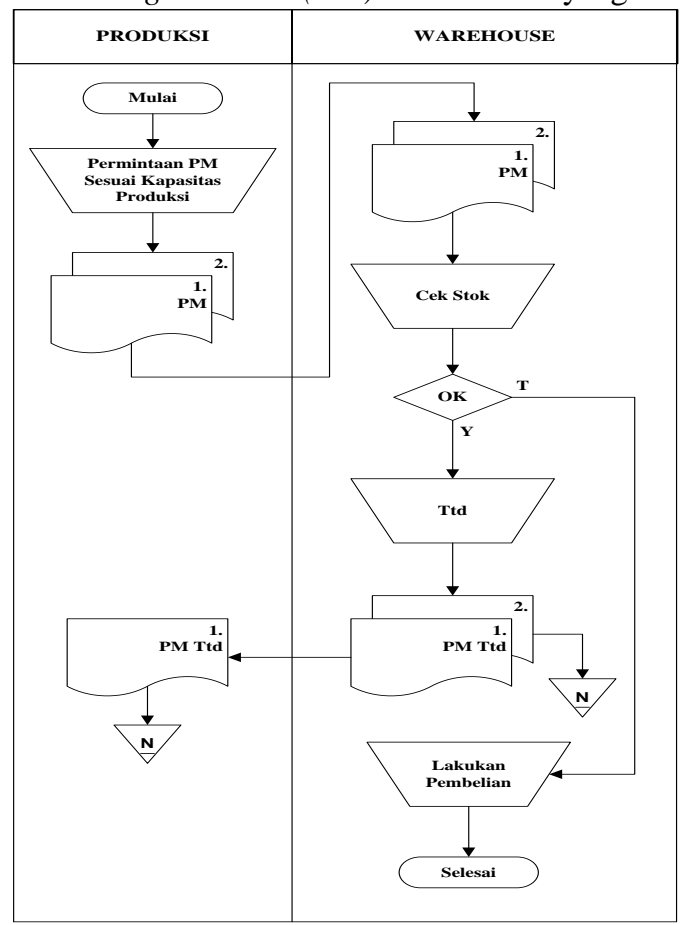

Gambar 1 Flow of Document Prosedur Pengeluaran Barang

Tabel 1 Contoh Laporan Pengeluaran Barang

\begin{tabular}{|c|c|c|c|c|c|c|}
\hline \multicolumn{7}{|c|}{ LAPORAN PENGELUARAN BARANG } \\
\hline NO & TANGGAL & ITEM & JUMLAH & UOM & DEPARTEMEN & REQUESTER \\
\hline 1 & $01 / 08 / 2015$ & SEPARATOR PLASTIC TOP/BOTTOMSTAN & 30 & $P C$ & PRODUKSI & AMIN \\
\hline 2 & $01 / 08 / 2015$ & AIRBAG C $1000 \times 2000$ & 25 & $P C$ & PRODUKSI & INDRA \\
\hline 3 & $05 / 08 / 2015$ & KLIP BS SPOOL & 2 & BOX & PRODUKSI & ZAENAL \\
\hline 4 & 06/08/2015 & Isi Staples Strongman $3518 \mathrm{U}$ & 5 & BOX & PRODUKSI & HADI \\
\hline 5 & 08/08/2015 & TELESCOPIC SW & 62 & $P C$ & PRODUKSI & TAUFIK \\
\hline
\end{tabular}

\section{Pembelian}

1. Warehouse

a. Membuat form Request Order (RO) dalam rangkap 2.

b. Menyerahkan form Request Order (RO) kepada Logistic Manager untuk disetujui. 
c. Menerima form Request Order (RO) yang sudah disetujui Operational Manager.

2. Logistic Manager

a. Menerima form Request Order (RO) dari Warehouse.

b. Menandatangani form Request Order (RO), kemudian diserahkan pada Operational Manager.

3. Operational Manager

a. Menerima form Request Order (RO) yang sudah ditandatangani oleh Logistic Manager.

b. Memberikan approval dengan menandatangani form Request $\operatorname{Order}(R O)$, kemudian diserahkan pada Purchasing.

4. Purchasing

a. Menerima form Request $\operatorname{Order}(R O)$ yang sudah disetujui oleh Operational Manager.

b. Membuat form Purchase $\operatorname{Order}(P O)$ dalam rangkap 2.

c. Menyerahkan form Purchase Order (PO) kepada Purchasing Manager.

d. Menerima form Purchase Order (PO) yang sudah disetujui oleh General Manager.

3. Purchasing Manager

a. Menerima form Purchase Order (PO) dari Purchasing.

b. Menandatangani form Purchase Order (PO), kemudian diserahkan pada General Manager.

4. General Manager

a. Menerima form Purchase Order (PO) yang sudah ditandatangani oleh Purchasing Manager.

b. Menandatangani form Purchase Order (PO), kemudian form Purchase Order (PO) lembar ke-1 diserahkan pada Supplier dan lembar ke-1 diserahkan pada Purchasing.

5. Supplier

Menerimaform Purchase Order (PO) yang sudah disetujui oleh General Manager.

\section{Penerimaan Barang}

1. Supllier

a. Mengirim barang sesuai dengan Purchase Order (PO).

b. Menyerahkan form Purchase Order (PO) ke Warehouse.

2. Warehouse

a. Menerimabarang dan form Purchase Order (PO) dari Supllier, kemudian dilakukan pengecekan kualitas dan jumlah barang apakah sesuai dengan $P O$ atau tidak.

b. Jika barang sesuai dengan $P O$, maka barang disimpan di gudang, kemudian buat form Tanda Terima Barang dalam rangkap 2, lembar ke-1 diserahkan pada Supllier dan lembar ke-2 beserta form Purchase Order (PO) diserahkan pada Purchasing. Jika tidak sesuai, maka diterbitkan form Komplen kemudian diserahkan pada Purchasing.

3. Purchasing

a. Menerima form Tanda Terima Barang lembar ke-2 dan form Purchase Order (PO) dari Warehouse.

b. Menerima form Komplen dari Warehouse, kemudian dilakukan tindak lanjut dengan mengirim kompenan pada Supplier. 


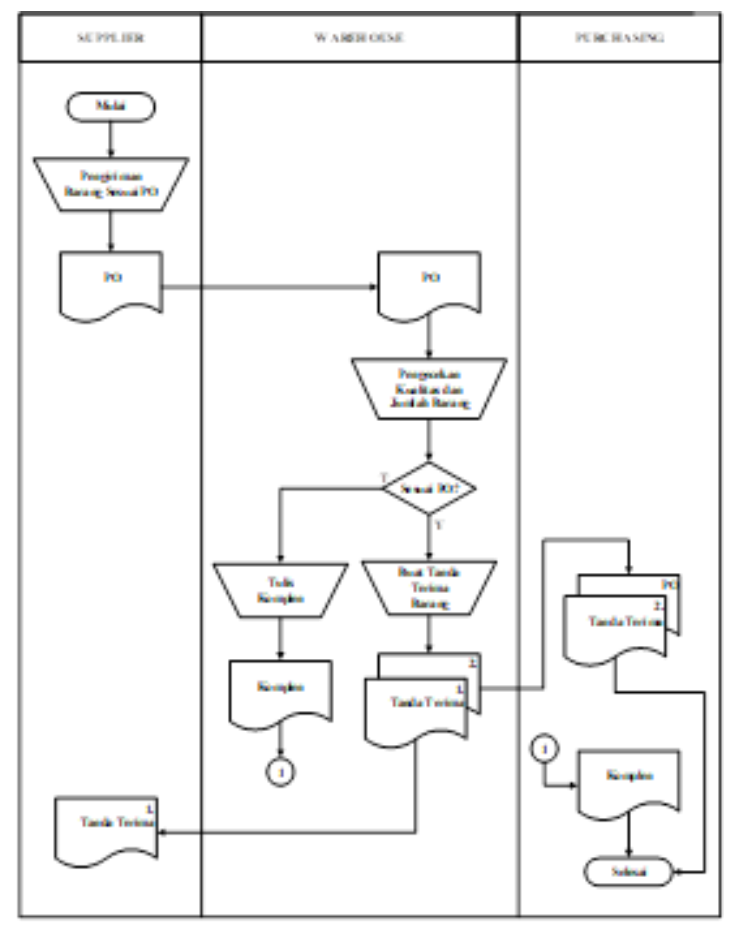

Gambar 2 Flow of Document Prosedur Penerimaan Barang

\section{Identifikasi Permasalahan}

Setelah melakukan analisa terhadap sistem persediaan barang yang berjalan di PT. Bekaert Indonesia,maka permasalahan yang muncul adalah tidak adanya sistem yang mengatur dan menjaga stok maupun kualitas dari packing materials yang dipesan ataupun yang dikeluarkan untuk proses produksi.

\section{Pemecahan Masalah}

Untuk menghadapi permasalahan-permasalahan yang terjadi di PT. Bekaert Indonesia pada sistem pengendalian barang maka perlu adanya pemecahan masalah. Adapun alternatif pemecahan masalah tersebut sebagai berikut:

1. Merancang dan membangun Sistem inventory yang dapatmengatur dan menjaga stok maupun kualitas dari packing materials, baik yang dipesan ataupun yang dikeluarkan serta menerapkannya ke dalam sebuah aplikasi berbasis Visual Basic.Net dengan database menggunakan SQL Server 2005 sehingga kinerja pada bagian logistik lebih efektif dan efisien.

2. Disediakan data login pengelola/ administrator untuk menjamin akan keamanan data perusahaan.

3. Pada aplikasi tersebut disediakan juga sistem pencarian data sehingga volume transaksi yang besar tidak menjadi kendala karena data tersebut dapat dicari dengan cepat dan akurat oleh sistem.

\section{RANCANGAN SISTEM YANG DIUSULKAN}

\section{A. Usulan Sistem yang Baru}

Prosedur sistem usulan yang diusulkan tidak banyak mengalami perubahan dari sistem berjalan yang telah ada, hanya saja pada sistem usulan pengolahan data inventory control yang mencakup pembelian Material, penerimaan Material, persediaan Material, safety stock, dan pengeluaran Material sudah dimasukan pada aplikasi dan disimpan dalam database, semua data tersebut sudah dilakukan secara terkomputerisasi dengan program aplikasi berbasis VB.Net.

Untuk mewujudkan sistem informasi inventory control berbasis VB.Net maka dengan ini memberikan solusi berupa pembuatan program yang sederhana, agar mudah di pahami dan mudah di jalankan bagi setiap orang yang ingin menggunakannya. Pembuatan program yang sederhana ini dengan menggunakan aplikasi Microsoft Visual Studio 2008 dan database menggunakan SQL Server 2005. 


\section{Usulan Sistem Baru}

Berdasarkan hasil penelitian yang lakukan di PT. Bekaert Indonesia, bahwa sistem inventory control pada PT. Bekaert Indonesia masih belum maksimal. Solusi yang akan diberikan adalah dengan membuat suatu suatu sistem informasi inventory control berbasis Microsoft Visual Basic (VB.Net) dengan menggunakan database MySQL.

\section{a. Gambaran Sistem Usulan}

Sistem baru yang diusulkan difokuskan kepada estimasi kebutuhan Material, pemesanan Material, penerimaan Material, persediaan Material, safety stock, dan pengeluaran Material yang hanya dapat diakses oleh petugas yang mempunyai hak akses dengan menggunakan username dan password demi keamanan data. Peranan sistem ini sangatlah penting, karena dengan menggunakan sistem informasi inventory control berbasis VB.Net, akan memudahkan dalam mengolah dan memproses data dengan cepat, dan akurat.

\section{b. Sasaran/Informasi Sistem Usulan}

Sasaran dari sistem yang diusulkan, diharapkan dapat mendukung sistem informasi inventory control, dengan memudahkan pemasukan data dan keamanan data yang dihasilkan, sehingga dapat meminimalisir kesalahan dalam input data yang menyebabkan ketidak sesuaian antara data yang diinput dengan dokumen pendukung, karena efek dari kesalahan input dapat berakibat fatal.

\section{Perancangan Sistem Usulan}

Perancangan sistem informasi inventory control yang diusulkan mencakup beberapa prosedur yaitu:

\section{Pembelian Material}

a. Warehouse

1) Melakukan pembelian dengan input data Request $\operatorname{Order}(R O)$ dalam rangkap 2.

2) Menyerahkan Request Order (RO) kepada Logistic Manager untuk di approved.

3) Menerima Request Order (RO) yang sudah di approved Operational Manager.

b. Logistic Manager

1) Menerima Request Order (RO) dari Warehouse.

2) Menandatangani Request Order $(R O)$, kemudian diserahkan pada Operational Manager.

c. Operational Manager

1) Menerima Request Order (RO) yang sudah ditandatangani oleh Logistic Manager.

2) Melakukan approval dengan menandatangani Request $\operatorname{Order}(R O)$, kemudian diserahkan pada Purchasing.

d. Purchasing

1) Menerima Request Order $(R O)$ yang sudah di approved oleh Operational Manager.

2) Input data Purchase Order (PO) dalam rangkap 2.

3) Menyerahkan Purchase Order (PO) kepada Purchasing Manager.

4) Menerima Purchase Order (PO) yang sudah di approved oleh General Manager.

e. Purchasing Manager

1) Menerima Purchase Order (PO) dari Purchasing.

2) Menandatangani Purchase Order (PO), kemudian diserahkan pada General Manager.

f. General Manager

1) Menerima Purchase Order (PO) yang sudah ditandatangani oleh Purchasing Manager.

2) Melakukan approval dengan menandatangani Purchase Order (PO), kemudian Purchase Order (PO) lembar ke-1 diserahkan pada Supplier dan lembar ke-1 diserahkan pada Purchasing.

g. Supplier

Menerima Purchase Order (PO) yang sudah di approved oleh General Manager. 


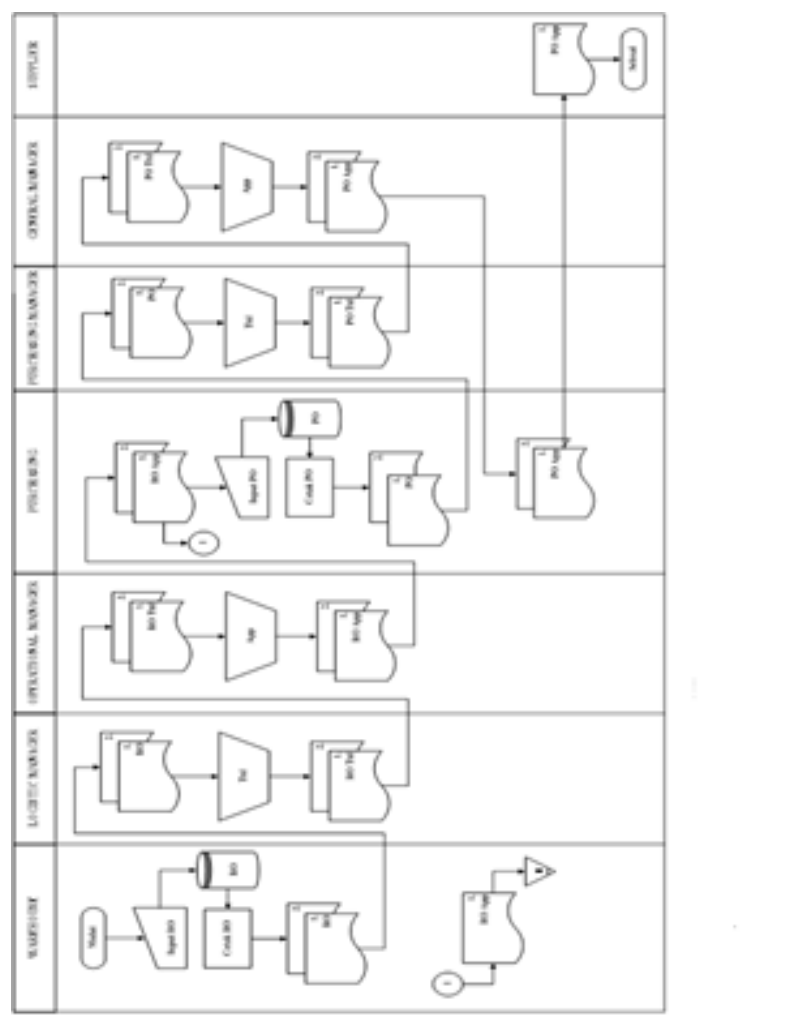

Gambar 3 Flow of System Pembelian Material

\section{Penerimaan Material}

\section{a. Supplier}

1) Mengirim barang sesuai dengan Purchase $\operatorname{Order}(\mathrm{PO})$.

2) Menyerahkan Purchase Order (PO) ke Warehouse.

b. Warehouse

1) Menerima barang dan Purchase $\operatorname{Order}(P O)$ dari Supplier, kemudian dilakukan pengecekan kualitas dan jumlah barang apakah sesuai dengan $P O$ atau tidak.

2) Jika barang sesuai dengan $P O$, maka barang disimpan di gudang, kemudian input Tanda Terima Barang dan dicetak dalam rangkap 2, lembar ke-1 diserahkan pada Supplier dan lembar ke-2 beserta dan Purchase Order (PO) diserahkan pada Purchasing. Jika tidak sesuai, maka di input data Komplen kemudian diserahkan pada Purchasing.

c. Purchasing

1) Menerima Tanda Terima Barang lembar ke-2 dan Purchase Order (PO) dari Warehouse.

2) Menerima Komplen dari Warehouse, kemudian dilakukan tindak lanjut dengan mengirim kompenan pada Supplier. 


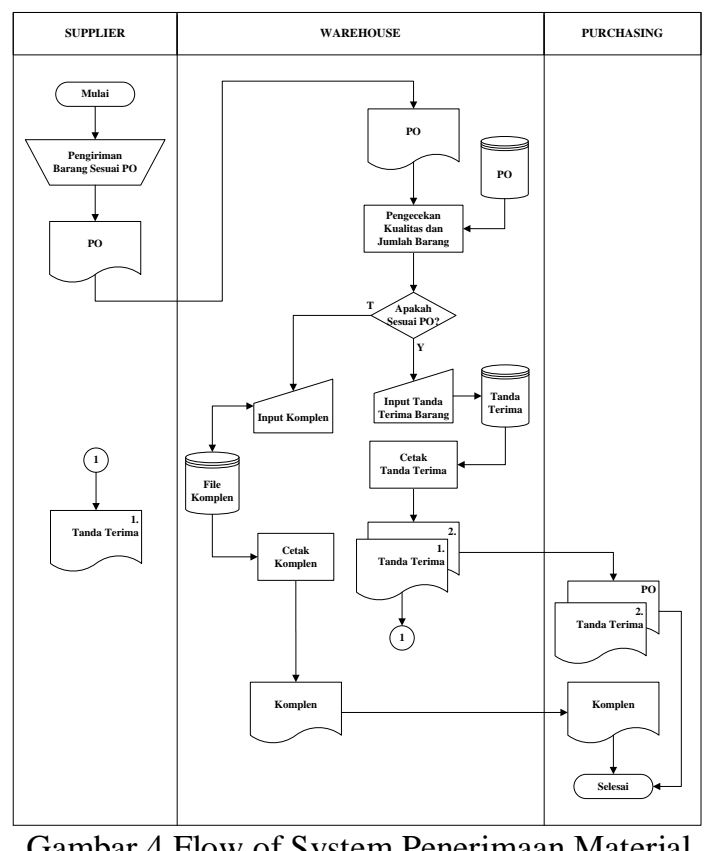

\section{Pengeluaran Material}

\section{a. Produksi}

1) Melakukan estimasi kebutuhan Material dengan menginput data estimasi, berdasarkan data estimasi tersebut, kemudian dilakukan permintaan Material dengan input data Packing Material (PM), kemudian dicetak dalam rangkap 2.

2) Menyerahkan Packing Material (PM) ke Warehouse.

3) Menerima Packing Material (PM) lembar ke-1 yang sudah ditandatangani oleh Warehouse, kemudian diarsip menurut nomor.

b. Warehouse

1) Menerima Packing Material (PM) dari Produksi, kemudian input pengeluaran Material, berdasarkan data pengeluaran Material tersebut, maka dicek safety stok Material apakah masih aman atau tidak aman. Jika masih aman, maka Packing Material (PM) ditandatangani. Jika tidak aman, maka dilakukan pembelian.

2) Menyerahkan Packing Material (PM) lembar ke-1 yang sudah ditandatangani kepada Produksi. 


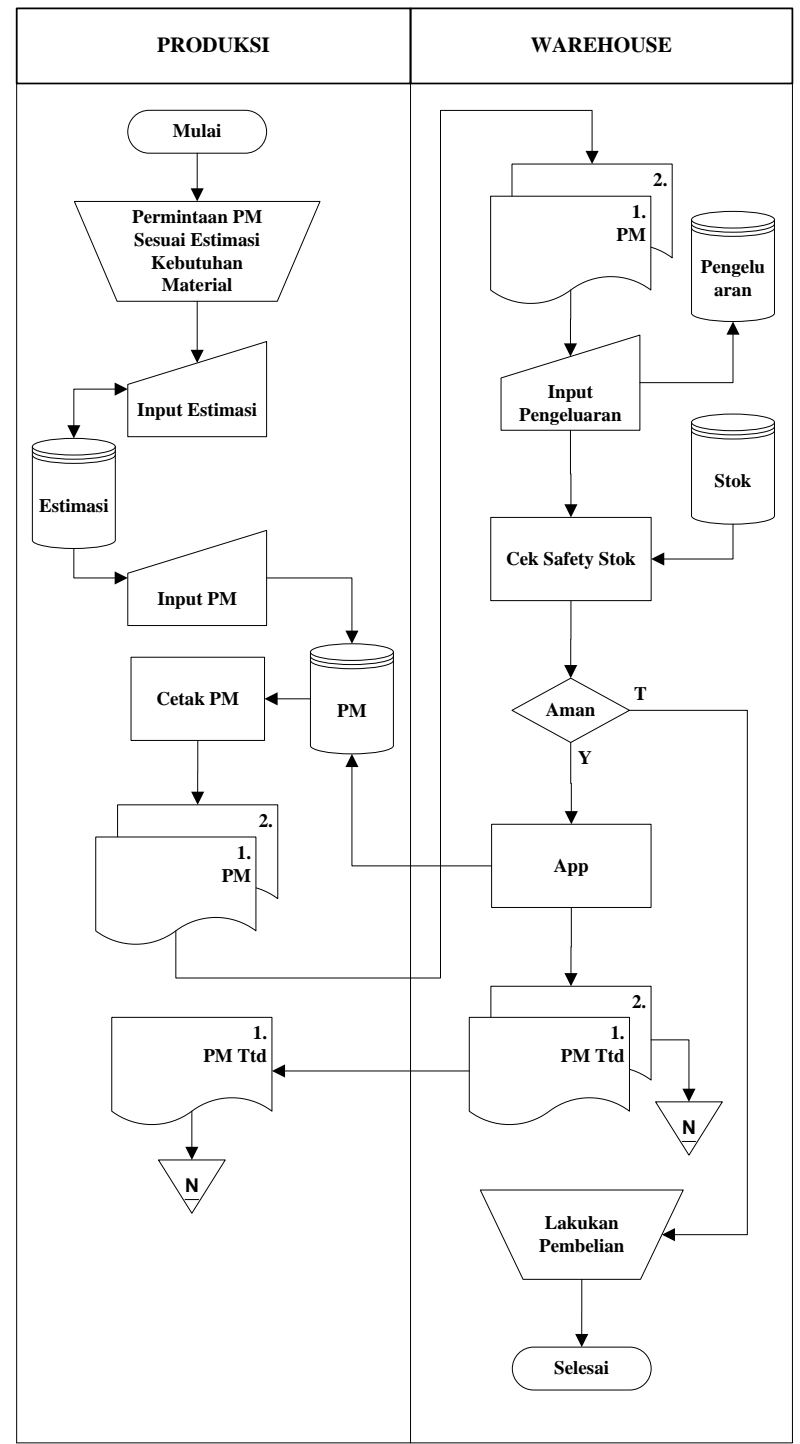

Gambar 5 Flow of System Pengeluaran Material

\section{Data Flow Diagram (DFD)}

\section{Diagram Kontek}

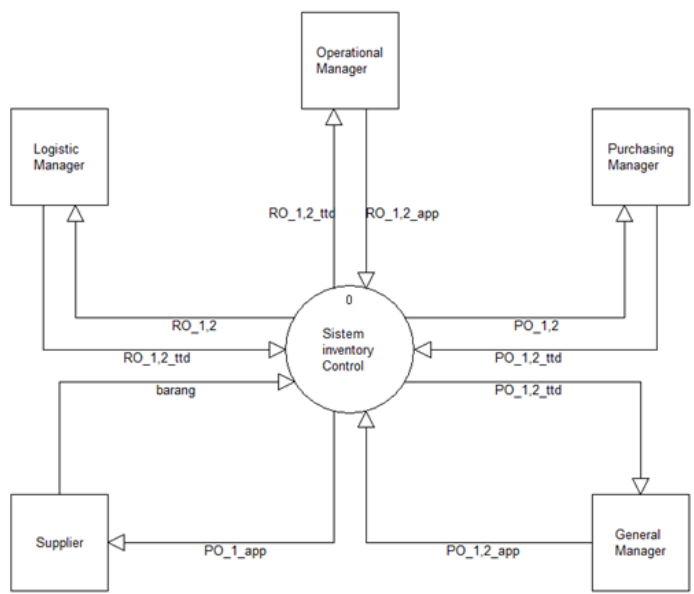

Gambar 6 Diagram Kontek

Pada gambar 5 menjelaskan bahwa Logistic Manager, Operational Manager, Purchasing Manager, Supplier, dan General Manager merupakan external entity, sedangkan 
internal entity adalah bagian yang mengelola sistem invetory control.

\section{DFD Level 0}

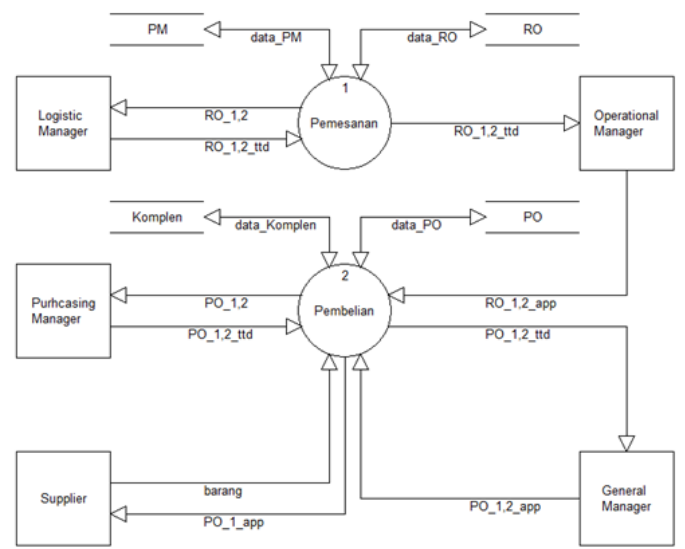

Gambar 7 DFD Level 0

\section{Entity Relationship Diagram (ERD)}

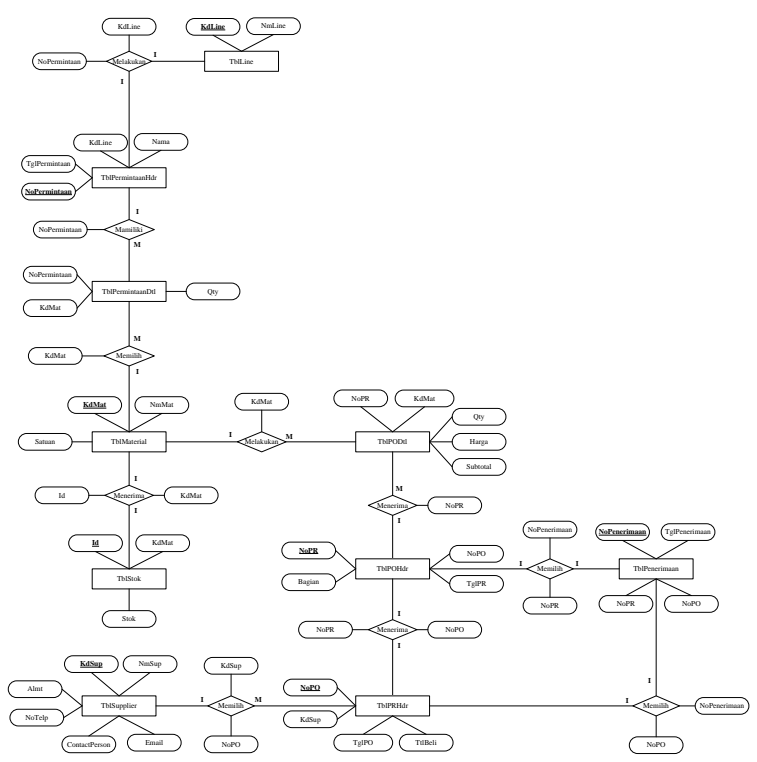

\section{KESIMPULAN DAN SARAN}

\section{Kesimpulan}

Dari uraian perancangan system inventory control berbasis VB.Net pada PT Bekaert Indonesia, maka dapat diambil kesimpulan:

1. Sistem inventory control ini mempunyai fasilitas-fasilitas yang dapat membantu dalam penginputan maupun pencarian data secara cepat.

2. Sudah tidak diragukan lagi efisiensi dari sistem ini karena semua laporan, pencatatan transaksi dan lain-lain sudah terarsip dengan baik di database tidak menggunakan kertas lagi, maka terjadinya kehilangan atau kesalahan kecil sekali, dan pemborosan dapat diminimalisir.

3. Peningkatan dari segi informasi juga tercapai seperti pada saat memerlukan laporan data penerimaan dan pengeluaran material, informasi yang dihasilkan lebih relevan dan jauh dari kesalahan.

4. Sistem informasi ini dapat membantu pengelola untuk memantau, mengatur, dan menjaga stok maupun kualitas dari packing materials yang dipesan ataupun yang dikeluarkan untuk proses produksi sehingga dari pihak manajemen dapat mengondisikan agar tidak salah dalam menentukan suatu keputusan.

\section{Saran}

Agar aplikasi inventory control berbasis VB.Netini kedepannya lebih baik, maka yang dapat disarankan adalah: 
1. Mengadakan evaluasi terhadap sistem inventory controlini untuk pengembangan selanjutnya.

2. Agar kegiatan yang dilakukan dapat memberikan hasil yang maksimal maka perlu ditingkatkan ketelitian personil dalam pengolahan data untuk menghindari kesalahankesalahan.

3. Sistem harus dikembangkan lebih lanjut dengan meminimalisir terjadinya kesalahan dalam memproses data inventory

4. Control dengan memaksimalkan sintaks dan tampilan message box sebagai peringatan terjadinya kesalahan.

\section{DAFTAR PUSTAKA}

[1] A.S,Rosa dan Shalahuddin, M. Modul Pembelajaran: Rekayasa Perangkat Lunak. Modula, Bandung.2011.

[2] Connolly, T., \& Begg, C. Database Systems: A Practical Approach to Design, Implementation, and Management. (5th Edition). Boston: Pearson Education.2010.

[3] Haming, Murdifin dan Mahfud Nurnajamuddin. Manajemen Produksi Modern (Operasi Manufaktur dan Jasa). Edisi Kedua Cetakan Pertama. Penerbit: PT Bumi Aksara. Jakarta.2012.

[4] Indrajani. Perancangan Basis Data Dalam Allin1. Elex Media Komputindo. Jakarta. 2011, p48.

[5] Ishak, Aulia, Manajemen Operasi, Yogyakarta: Graha Ilmu, 2010, p159.

[6] Kadir, Abdul. Pengenalan Sistem Informasi. Andi. Yogyakarta.2009.

[7] Kusbianto, Deddy. Analisis dan Perancangan Sistem Informasi. STMIK Yadika, Bangil .2010.

[8] Mulyana, Hendrik. Analisa dan Perancangan Sistem Optimalisasi Perhitungan Kebutuhan Bahan Pendukung Produksi di PT. NT Piston Ring Indonesia. STMIK Rosma, Karawang.2013.

[9] Priyatno, Antok. Rancang Bangun Aplikasi Perhitungan Kebutuhan Bahan Baku pada PT. NT Piston Ring Indonesia. STMIK Rosma, Karawang. 2013.

[10] Satzinger, J. W., Jackson, R. B., \& Burd, S. D. System Analysis And Design in A Changing World. Boston, MA, Course Technology.2010, p6.

[11] Stair, M. Ralph, George W. Reynolds. Principles of Information Systems: A Managerial Approach. (9 ${ }^{\text {th }}$ edition). Australia: Thomson Course Technology. 2010, p35.

[12] Widodo, Puji. Analisis Pengendalian Persediaan Bahan Baku Impor pada PT. Multi Strada Arah Sarana, Tbk. STMIK Rosma, Karawang. 2013.

[13] Wijayanti, Eri. Analisa dan Perancangan Sistem Informasi Persediaan Berbasis Webpada PT. Osimo Indonesia. STMIK Rosma, Karawang.2014.

[14] Yakub. Pengantar Sistem Informasi.Yogjakarta: Graha Ilmu. 2012, p8. 